NBER WORKING PAPER SERIES

\title{
DO REQUIRED MINIMUM DISTRIBUTIONS MATTER? THE EFFECT OF THE 2009 HOLIDAY ON RETIREMENT PLAN DISTRIBUTIONS
}

\author{
Jeffrey R. Brown \\ James Poterba \\ David Richardson
}

Working Paper 20464

http://www.nber.org/papers/w20464

\author{
NATIONAL BUREAU OF ECONOMIC RESEARCH \\ 1050 Massachusetts Avenue \\ Cambridge, MA 02138 \\ September 2014
}

We are grateful to Ben Sprung-Keyser and especially to Ben Bissette for outstanding assistance with data analysis, to the TIAA-CREF Institute (Richardson) and the National Science Foundation (Poterba) for research support, and to William Gentry, Alan Gustman, Brigitte Madrian, Steven Venti, Mark Warshawsky, Anthony Webb, David Wise, and seminar participants at Brandeis, the Congressional Budget Office, the 2014 NBER Summer Institute, and the 2014 Trans-Atlantic Public Economics Symposium for helpful discussions. Brown is a trustee of TIAA, and Poterba is a trustee of CREF. TIAA-CREF is a provider of investment and retirement income security products. This paper represents the views of the authors, and it does not necessarily reflect the views of the institutions with which they are affiliated or of the National Bureau of Economic Research.

At least one co-author has disclosed a financial relationship of potential relevance for this research. Further information is available online at http://www.nber.org/papers/w20464.ack

NBER working papers are circulated for discussion and comment purposes. They have not been peerreviewed or been subject to the review by the NBER Board of Directors that accompanies official NBER publications.

(C) 2014 by Jeffrey R. Brown, James Poterba, and David Richardson. All rights reserved. Short sections of text, not to exceed two paragraphs, may be quoted without explicit permission provided that full credit, including $\odot$ notice, is given to the source. 
Do Required Minimum Distributions Matter? The Effect of the 2009 Holiday On Retirement

Plan Distributions

Jeffrey R. Brown, James Poterba, and David Richardson

NBER Working Paper No. 20464

September 2014

JEL No. H2,J14,J26

\begin{abstract}
This paper investigates how the 2009 one-time suspension of the Required Minimum Distribution (RMD) rules associated with qualified retirement plans affected plan distributions at TIAA-CREF, a large retirement services provider. Using panel data on retirement plan participants at TIAA-CREF, we find that roughly one third of those who were affected by minimum distribution rules discontinued their distributions in 2009. The results also show relatively small differences in the suspension probability between those who had 2008 distributions equal to the RMD amount, and might be classified as facing a binding RMD constraint, and those who were taking distributions in excess of the RMD amount before the distribution holiday. The probability of suspension declines substantially with age and rises modestly with economic resources. We find that individuals taking monthly distributions are less likely to suspend distributions than those taking annual distributions, particularly at higher wealth levels. This pattern is consistent with those who choose monthly distributions being more likely to use their distributions to finance consumption. We supplement these results based on administrative record data on retirement plan participants with survey evidence on participant attitudes that affected decisions about suspending distributions. Our findings provide guidance on the revenue consequences of changing RMD rules and offer insights about the role of various behavioral considerations, such as inertia, in modeling distribution behavior.
\end{abstract}

Jeffrey R. Brown

Department of Finance

University of Illinois at Urbana-Champaign

515 East Gregory Drive

Champaign, IL 61820

and NBER

brownjr@illinois.edu

James Poterba

Department of Economics, E17-214

MIT

77 Massachusetts Avenue

Cambridge, MA 02139

and NBER

poterba@nber.org
David Richardson

TIAA-CREF Institute

8500 Andrew Carnegie Blvd.

Charlotte, NC 28262

dprichardson@tiaa-cref.org 
Traditional tax-qualified defined contribution (DC) retirement plans in the United States, such as Individual Retirement Accounts (IRAs) and employer-sponsored 401(k) and 403(b) plans, were created to provide incentives for individuals to save money during working life in order to help them achieve a reasonable living standard in retirement. These plans allow workers to defer taxation of contributions and accruing investment income within the qualified plan during their working life. Distributions from these plans during retirement are taxed as ordinary income. Deferring constructive receipt of otherwise taxable income on assets held within qualified DC plans provides consumption tax treatment to these assets, while operating within an income tax system.

There is a long regulatory tradition of limiting qualified plan participants' capacity to use these plans as a means of avoiding taxation on assets that are not needed to support retirement consumption. The tension between the goals of promoting retirement saving and limiting revenue costs is evident in the structure of the Required Minimum Distribution (RMD) rules that apply to tax-qualified plans. The RMD rules require plan participants to withdraw a minimum percentage of their account balance in each year once they reach a specified age.

Warshawsky (1998) describes the history of regulations on tax-qualified plans that have effectively required plan assets to be distributed to participants over some period of time after retirement or the attainment of a particular age. In 1962, Congress established formal distribution requirements for Keogh plans, tax-qualified plans for self-employed individuals, requiring plan owners to begin taking distributions by the later of the year in which they retired or the year in which they reached age $701 \frac{1}{2}$. Although what led to the choice of age $70 \frac{1}{2}$ in 1962 is not clear, it remains the key trigger point for current RMD rules despite significant increases in life expectancy over the intervening half a century. 
RMD rules now apply to virtually all tax-qualified retirement savings plans, including 401(k) plans, 403(b) plans, IRAs, and numerous other defined contribution plans. These rules limit the revenue cost of tax deferral and help to focus the tax subsidy for saving on accumulations for retirement. Soled and Wolk (2000) describe the rules in detail, and also characterize the various tax-planning approaches that account holders might use to limit the impact of these rules. Some Roth-style accounts are exempt from the RMD rules. Contributions to these accounts are made with after-tax rather than pre-tax dollars, and withdrawals are not taxed. As with other tax-qualified plans, account holders are not taxed on accruing capital income and therefore receive consumption tax treatment. Because the basis in Roth accounts was fully taxed when contributed, and withdrawals are not taxed, the timing of withdrawals from these accounts does not affect income tax revenues in the way that withdrawals from traditional tax-qualified accounts do. RMD rules apply to Roth 401(k) and 403(b) accounts, but not to Roth IRAs. For the latter, while there are no required distributions during the lifetime of the account for the participant who accumulated the account balance, or for the participant's spouse if he or she inherits the account, RMD rules do apply to inherited Roth IRAs when someone other than a spouse is the beneficiary.

RMD regulations are one of many requirements that retirement plans must meet in order be "tax-qualified," i.e., to allow their participants to exclude plan income from their taxable income. There are also limits on the amount that participants can contribute to these plans each year, restrictions on how and when funds can be withdrawn without paying penalties, and rules governing the share of total plan contributions that can go to highly compensated employees. Each of these and other parameters of the qualified plan system can affect the evolution of participant contributions and account balances, and therefore federal revenues. The extent to 
which these plan qualification requirements affect federal revenue depends on how they influence participant behavior.

It can be difficult to estimate the behavioral responses to a marginal change in plan qualification rules because many aspects of the law and regulations can change at one time, and because the number of policy changes is relatively small. One policy change that does lend itself to study took place in 2009, when, as part of the Worker, Retiree, and Employer Recovery Act of 2008 - the "stimulus bill" - Congress suspended the RMD rule for qualified plans for one year. The intent was to allow retirement plan participants whose account balances had been substantially reduced by falling asset prices during the financial crisis to skip a year of required payouts. This provision was viewed as helping retirees preserve their retirement security by not forcing them to sell assets in the depths of the crisis. The Joint Committee on Taxation estimated a one-year revenue cost of about $\$ 3.8$ billion, which would be consistent with a projected decline in distributions of $\$ 19$ billion and an average tax rate of $20 \%$ on these distributions, or a decline of $\$ 15.2$ billion and a tax rate of $25 \%$.

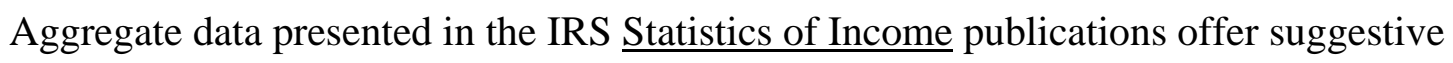
evidence on the impact of the distribution holiday. Taxable distributions from IRAs, which are just one, but a significant, class of tax-qualified accounts, declined 16.7\% from 2008 to 2009. These distributions totaled $\$ 148$ billion in 2007, $\$ 162$ billion in 2008, $\$ 135$ billion in 2009, and \$194 billion in 2010. The number of participants taking withdrawals also declined. It totaled 10.7 million in 2007, 11.3 million in 2008, 9.7 million in 2009, and 12.5 million in 2010.

Although these data suggest a substantial impact of the distribution holiday, it is difficult to draw firm conclusions from them for three reasons. First, the distribution holiday coincided with a sharp decline in asset values generally and in the account balances of tax-qualified plan 
participants in particular. This wealth effect may have affected distribution patterns, and would likely have resulted in a decline in the amount distributed even in the absence of a distribution holiday. Second, the aggregate data may confound the distribution holiday with another policy change that allowed individuals to convert traditional IRA assets to Roth IRAs while deferring half of the associated tax liability for a year. This provision offered more-attractive-than-usual tax treatment for conversions. Finally, the published IRS data pertain only to IRAs. These accounts are not employer-sponsored, and it is possible that there are differences in the behavior of participants in these accounts and in employer-sponsored plans such as 401(k)s and 403(b)s.

In this paper, we use a combination of administrative records and survey data to examine distribution patterns of participants in 403(b) plans who were subject to RMD rules prior to 2009, and who were eligible to suspend distributions during the 2009 holiday. We study the participants at TIAA-CREF, a large provider of retirement income and retirement services for employees at nonprofit institutions. Our data span the 2007-2010 period, making it possible to compare participant behavior before, during, and after the distribution holiday. Using administrative records on withdrawal activity, we estimate the probability that retirement plan participants who had taken required distributions in 2008 suspended their distributions during the 2009 holiday, and we explore the effect of a limited number of covariates on suspension choices. We find that roughly one third of participants suspended their distributions. We supplement this analysis with an email survey of a sub-sample of these participants, and explore the underlying motivations for suspending or not suspending distributions in 2009.

Our findings advance the analysis of required minimum distribution rules in three ways. First, we provide some of the first participant-level evidence on how the RMD rules affect distributions from qualified plans. Second, we describe the heterogeneity in this response across 
plan participants with various characteristics. Finally, we estimate the change in the percentage of qualified plan assets withdrawn when the RMD rules were, and were not, in force.

Our analysis may guide policymakers with regard to possible modifications of the RMD rules, which are currently the subject of much discussion. For example, both the U.S. Departments of Treasury and Labor have recently expressed interest in promoting increased annuitization of assets within qualified plans. The Department of Labor has released proposed rules to require that defined contribution plans provide income illustrations rather than just account balances as part of quarterly or annual account statements. In July 2014, the U.S. Treasury Department issued final rules that allow qualified plan participants to use up to 25\% of their plan balance, to a limit of $\$ 125,000$, to purchase longevity annuities that would not begin payouts until the participant reaches a later age, such as 80 or 85 . In the U.K, in contrast, policy has moved in precisely the opposite direction. While the U.S. has moved to facilitate annuitization, Mercer (2014) reports that, in 2014, the U.K. eliminated mandatory partial annuitization of retirement account balances and expanded saver discretion in withdrawing assets. These divergent policy directions underscore the importance of understanding how regulations affecting distribution practices affect participant behavior.

The paper is divided into five sections. The first describes the RMD rules that apply to tax-qualified retirement accounts and the 2009 distribution holiday. It also examines the relationship between the path of distributions specified by current U.S. regulations and the optimal consumption profile for an individual seeking to maximize late-life utility in the context of a stochastic lifecycle model. The goal of this comparison is to shed some light on whether the RMD profile might be close to the optimal profile, and therefore not a binding constraint on 
participant behavior. This section also describes the small prior literature that has considered the effects of distribution rules on participant behavior.

Section two describes our data set on TIAA-CREF participants who were taking required distributions in 2008, and who therefore were eligible to take advantage of the distribution holiday in 2009. It notes a number of challenges that arise in tracking withdrawal behavior over time, even with administrative record data. Section three documents a decline of roughly one third in the number of TIAA-CREF participants taking an RMD between 2008 and 2009, and it presents estimates of probit models that relate the probability of suspending distributions to various participant attributes. Surprisingly, the suspension behavior of those who appear to have been taking only the minimum distribution from their accounts, and those who were withdrawing larger amounts, is quite similar. We do find that those with higher qualified plan balances were more likely to suspend, as were those who previously were taking their annual distribution as a single payment rather than as regular monthly income.

The fourth section summarizes the findings from a survey that was sent to a subset of TIAA-CREF participants who were eligible to suspend their distributions in 2009. The survey included questions about participants' reasons for suspending, or not suspending, their payouts. The results offer some insight on the way participants view RMD rules and the importance of the associated distributions in supporting retirement consumption. A final section concludes and suggests several open research questions.

\section{Required Minimum Distribution (RMD) Rules and Retirement Consumption}

\subsection{Overview of RMD Rules}

The RMD rules stipulate that the holder of a tax-qualified qualified retirement account, except for a Roth IRA, must begin distributions no later than the later of April 1 of the year 
following the calendar year in which she turns $70^{1 / 2}$ or the year in which she terminates employment. The RMD rules specify that the distribution each year must exceed the participant's account balance at the end of the previous year divided by an "applicable distribution period" that depends on the participant's life expectancy and that of the qualified plan's beneficiary. Although the precise methods for calculating the size of required distributions have occasionally changed over time, the RMD amount has always been linked in some way to a measure of remaining life expectancy. The penalty for failure to take minimum distributions is an excise tax of $50 \%$ of the required, but undistributed, amount. This penalty provides a substantial incentive for participants to track their RMDs, and is one reason that many retirement plan providers prepare RMD estimates for their participants.

Table 1 shows the applicable distribution period for what the IRS labels a "uniform lifetime." This is the remaining lifetime that the account balance must be divided by for unmarried account owners, for married owners whose beneficiaries are spouses within ten years of their age, and for married owners whose spouses are not the beneficiary of their accounts. If the account holder is married and the account beneficiary is a spouse who is more than ten years younger, then the divisor is larger, allowing for slower draw-down of the account balance. There is yet another RMD table for beneficiaries of an inherited tax-qualified account.

Table 1 shows that for participants who are covered by the "uniform lifetime" table, the RMD in the first year after they turn $70 \frac{1}{2}$ (when they begin required distributions) is slightly less than $4 \%$ of the account balance. This annual distribution proportion rises as the participant ages, exceeding $5 \%$ at age 80 , approaching $9 \%$ at age 90 , and exceeding $15 \%$ for those who reach the age of 100 . 


\subsection{RMD Rules vs. Optimal Consumption Profiles}

In standard lifecycle models, consumers select their consumption paths to maximize the expected discounted value of lifetime utility.

$$
\operatorname{Max} \sum_{t=0}^{T} \frac{P_{t} \cdot U\left(C_{t}\right)}{(1+\delta)^{t}}
$$

where $P_{t}$ is the cumulative survival probability from time 0 to $t, \delta$ is the individual's subjective discount rate, and $\mathrm{Ct}$ is the flow of consumption in period t. It is common to assume that preferences exhibit constant relative risk aversion (CRRA):

$$
U\left(C_{t}\right)=\frac{\left(C_{t}-1\right)^{(1-\gamma)}}{1-\gamma}
$$

This maximization is constrained by a lifetime budget constraint

$$
W_{0}=\sum_{t=0}^{T} \frac{C_{t}}{(1+r)^{t}}
$$

and potentially by liquidity constraints that restrict the consumer's ability to transfer resources across periods. Such constraints may arise early in life if it is difficult to borrow against future earnings, or late in life when the present value of Social Security benefits, which cannot be

pledged as collateral, is an important component of wealth. The budget constraint becomes more complex in the presence of tax-qualified accounts that offer a return of $r$, and taxable accounts that offer a return of $\mathrm{r}(1-\tau)$, where $\tau$ is the effective tax rate on the participant's capital income, with constraints on the amount that can be contributed each period to the higher-return qualified account, and floors on withdrawals in some periods. Optimal behavior equates the expected discounted marginal utility of consumption at different ages. This is often referred to as “consumption smoothing,” although only in special circumstances does it imply equal consumption in all periods. Optimizing behavior can generate declining real consumption over 
time if the consumer's discount rate exceeds the market rate of interest or if the consumer faces high mortality rates and does not have access to actuarially fair annuities.

RMD rules do not specify a consumption trajectory, but rather specify the amount of wealth that must be withdrawn from a tax-qualified account at each age. A participant who does not wish to consume the full amount of an RMD always has the option of making the withdrawal from the tax-qualified account and investing the proceeds in a taxable account. RMDs are therefore best viewed as constraints on the fraction of their wealth that can be held in taxqualified accounts, rather than on the amount that must be consumed.

If an individual's desired consumption spending, minus other sources of income such as Social Security, exceeds the RMD amount at a given age, then withdrawals from tax-qualified accounts will not be constrained by the RMD rules. Such individuals would choose to withdraw more than the RMD amount in any case. The RMD rules should only constrain the tax-qualified account holdings of those for whom this inequality is reversed, and in such cases, they will require participants to draw down their tax-qualified accounts sooner than they would do in the absence of these rules. We will refer to individuals whose preferred consumption path and other income stream involves slower withdrawals from these accounts as "RMD constrained.” For them, RMDs can affect the consumption path by altering the marginal return on saving in some periods, shifting it from $r$ to $r(1-\tau)$, and by reducing their lifetime wealth because they cannot hold as much in the tax-deferred account as they would like to.

How can the lifecycle model inform the analysis of RMD rules? We can ask how the age profile of RMDs compares with the age-consumption profile that emerges from the optimizing model, as a way of understanding whether a participant who chose to set her consumption equal to the RMD amount would experience a substantial welfare loss. For a participant with no 
wealth other than their qualified account, and no income from other sources such as Social Security, consuming exactly the amount withdrawn under the RMD rules amounts essentially to consuming their "wealth/remaining life expectancy according to the IRS tables" in each period. Analysis of a problem such as that posed in equations (1) through (3) suggests that this is only optimal in a very narrow set of circumstances. In particular, three conditions must hold: (i) the participant must have log utility (CRRA coefficient $=1$ ), (ii) $r=\delta=0$, and (iii) the participant's expected mortality rates must equal those used by the IRS in constructing the RMD rules. In other circumstances, the optimal consumption path will diverge from the path of RMDs, and the participant would want to deviate from the RMD withdrawal pattern to achieve that outcome. For example, an individual who believed she faced a significantly lower mortality risk than the IRS life table assumes, and therefore expected to live longer, might choose to consume less each year than the RMD amounts.

Figure 1 shows the time path of withdrawals associated with the "uniform lifetime" RMD rules under the assumption that they start with $\$ 100,000$, earn a $5 \%$ annual nominal return, and face a $2.5 \%$ annual inflation rate. The real value of withdrawals rises, then declines, and it falls steeply at older ages. A consumption trajectory equal to this time profile would be optimal only under a very restrictive set of conditions. Sun and Webb (2013) compute the present discounted value of remaining lifetime utility, conditional on wealth, that an individual would obtain by following an optimal consumption trajectory beginning at age 70, and they compare this with the utility stream from setting consumption in each year equal to the RMD amount from the same wealth stock at age 70 . The results suggest that following the strategy of consuming the amount specified by the RMD would be tantamount to a wealth reduction, assuming an optimal consumption profile, of between 17 and $44 \%$. 
While the lifecycle model is a helpful starting point for analyzing how the RMD profile compares with an optimal consumption profile, many studies in the behavioral economics literature suggest differences between observed retirement saving and asset drawdown and that implied by optimization in stochastic lifecycle models. In particular, Madrian and Shea (2001) and many subsequent studies suggest that default options have an important effect on participation in 401(k) plans, Lusardi and Mitchell (2014) suggest that many households lack basic financial literacy, and Brown, Kling, Mullainathan, and Wrobel (2013) suggest that choices about annuities and other financial products are sensitive to framing. In the context of RMDs, Sun and Webb (2013) discuss a number of "rules of thumb" that individuals appear to use in making retirement consumption decisions, including spending only capital income and not invading nominal principal, and the “ $4 \%$ rule,” often suggested by financial planners, that involves consuming $4 \%$ of wealth each year.

It is possible that some qualified plan participants may view RMD rules as a form of implicit financial planning advice. Indeed, the survey results that we present later suggest that about 51\% of TIAA-CREF participants who were taking plan distributions in 2008 "view the required minimum distribution as providing some guidance on how much you can spend each year for the rest of your life without running out of money."

This simple contrast between the optimal consumption path and the RMD path shows that the optimal timing of consumption over the lifetime may not match the pattern associated with RMDs. A consumer who wishes to defer consumption to very advanced ages might therefore find that the RMD rules constrain the amount that he would like to hold in his taxqualified account. 
Bequest motives provide another reason that RMD rules might bind. If a participant has a bequest motive, and wishes to leave some assets to her heirs, then absent RMD rules the optimal consumption plan would involve a balance in the tax-qualified account at the time of death. There are specialized rules that govern the required minimum distribution profile for beneficiaries who receive assets in tax-qualified plans. RMD rules were in large part designed to prevent the dynastic accumulation of wealth; the potential distortions that they may create in lifetime consumption patterns may be viewed as unintended consequences. It would be useful to distinguish between these alternative motives that participants might have for deferring the withdrawals from their tax-qualified plans, but it is not possible to do this using aggregate or administrative data. Our survey elicits some information on this issue.

\subsection{Previous Research on Distribution Patterns and RMDs.}

A number of previous studies have explored distributions from qualified accounts using a variety of data sources. Sabelhaus (2000), Bershadker and Smith (2006), and Bryant (2008) examine tax return data, which offer precise information on withdrawals, but very limited information on participant characteristics. Holden and Bass (2012) use administrative records from mutual funds that administer IRAs, Keogh plans, and corporate defined contribution plans. to track distribution patterns. Poterba, Venti and Wise (2013) use household survey data from the SIPP and HRS. These studies find that withdrawals from IRAs and other qualified plans rise sharply when participants reach age $701 / 2$, the age at which RMDs must begin for most participants. The studies all suggest that substantial numbers of tax-qualified plan participants do not take any distributions prior to this age, and that RMD rules presumptively affect the distribution pattern that they would otherwise choose. 
One puzzling finding from the studies using household survey data is the significant number of households with members over age $70 \frac{1}{2}$ and assets in tax-qualified accounts who do not report any distributions. A number of explanations have been advanced for this finding: the accounts could be Roth IRAs rather than traditional accounts that are subject to RMDs; the accounts could be employer-sponsored and the account holders may still be employed; the accounts may be held by another member of the household who is not yet subject to RMD rules; or the household may not be compliant with the RMD regulations. All of these factors may contribute to some degree, but they cannot be distinguished in most survey-based studies.

Studies that use tax return information do not have specific information on a participant's age. This makes it difficult to judge the fraction of qualified plan owners that are above the age at which RMDs must be taken, and consequently to determine whether these account holders are bound by the RMD rules. Our data, combined with the 2009 distribution holiday, provides a valuable opportunity to learn more about the behavior of qualified account holders who are subject to RMD rules.

\section{Background and Summary Statistics: Distributions from TIAA-CREF}

TIAA-CREF provides investment and retirement income services for workers in the notfor-profit sector, primarily in the higher education industry. It served over three million participants in 2010. Participants include faculty as well as staff at universities, medical institutions, public and private K-12 schools, and a number of other not-for-profit entities.

Our sample is based on the universe of 327,286 TIAA-CREF participants who received a retirement income distribution in 2008. Within this group, 81,826 participants had selected a Minimum Distribution Option (MDO) contract with TIAA-CREF. Another 27,796 participants took a lump-sum distribution, 26,719 chose to make systematic withdrawals, and the rest were 
receiving annuity payouts. The vast majority of these participants were in employer-sponsored 403(b) plans.

For participants who selected the MDO contract, TIAA-CREF calculates the annual RMD that must be withdrawn to satisfy the regulatory requirements, based on assets held within the TIAA-CREF system, and distributes this amount to the participant. The participant can choose to have this amount distributed on a monthly, quarterly, semi-annual or annual schedule. Participants can request distributions that are larger than the RMD amount, and they can change their distribution choices at any time during the year. Because our analysis requires information on distributions in 2008 (before the RMD holiday) as well as 2009 and 2010, and because we require a number of other participant attributes for our analysis, we ultimately analyze only a subset of those with MDO contracts in 2008. After we exclude the participants without information in all three years and with other missing data, we have a three-year balanced panel with 63,859 participants. None of the participants in our sample have Roth accounts. TIAACREF began offering these accounts during our sample period, and none of them would have been making distributions in 2008.

Table 2 provides descriptive statistics on our sample population. The average age in 2009 is 76.7 years, with primary participants being slightly older (77.4) on average and beneficiaries being, on average, significantly younger (61.6). Men comprise about 56.8\% and married persons about $67.4 \%$ of the sample. The table shows substantial heterogeneity in account balances: the mean balance for primary account holders in 2007 was $\$ 494,591$, but the median was less than half this value, $\$ 240,854$.

In 2008 , the mean RMD was $\$ 19,573$ and the median was $\$ 6,765$. For 2009 , the mean RMD fell by $\$ 8,433$ (43.1\%) to $\$ 11,140$, and the median RMD declined $\$ 5,102$ (75.4\%) to 
\$1,663. For "primary participants," i.e., those who accumulated the qualified plan balance, the mean RMD fell from $\$ 20,073$ to $\$ 11,500$, or a $42.7 \%$ decline. Although the dollar decline was smaller for beneficiaries, including surviving spouses, who inherited these accounts, the percentage decline was slightly larger. Overall, more than half of all beneficiaries stopped distributions in 2009. In 2010, when RMD rules were reinstated, the mean RMD was $102.6 \%$ of the mean 2008 level, although the median RMD was only about 91\% of the 2008 median level.

A key question concerning our sample is whether it is representative of the U.S. population with qualified accounts subject to RMDs. We explored this issue using data from the 2010 Survey of Consumer Finances. Among SCF respondents who were at least 71 years old, 4.8\% reported some assets in an employer-sponsored defined contribution account, such as a 401(k) or a 403(b) plan. A much larger percentage of this age group, 30.6\%, reported some assets in an IRA. Among those with employer-sponsored qualified plans, the mean value of the assets in these accounts is $\$ 255,488$. This refers to the total value of accounts, potentially from multiple employers. The median qualified plan balance is much lower: $\$ 36,000$. Both the mean and median for men in the 71+ age group is significantly higher than that for women. These statistics suggest that the TIAA-CREF participant sample that we analyze may not be fully representative: their account balances are larger than those of the general population. In the SCF data, the median account balance in the TIAA-CREF sample, $\$ 240$, 854, falls between the 80th and the 85th percentile of the qualified plan distribution.

Because our information on participants is limited to what is available in the administrative data, it is difficult for us to explore potential sources of the above-average balances of our sample participants. The larger account balances could arise from TIAA-CREF participants having higher lifetime incomes, higher savings rates, being more likely to contribute 
to a single retirement plan for their whole career, less likely to roll some or all of their accumulated assets into an IRA, or a combination of these factors. These comparison statistics suggest that caution is appropriate before generalizing our findings.

The TIAA-CREF participant population may be more representative of the future U.S. qualified plan participant population than of the current one, because many of the TIAA-CREF participants probably worked for employers who offered 403(b) plans for most of their careers. In contrast, current U.S. retirees outside the academic sector were likely to have been covered by a 401(k) plan, or eligible to contribute to an IRA, for only part of their working career. The sharp growth of 401(k)s began in the early 1980s; IRAs were introduced in 1981.

\section{TIAA-CREF Participant Response to the 2009 RMD Holiday}

\subsection{Univariate Results}

TIAA-CREF sent multiple mailings and other communications to MDO contract holders after the RMD holiday was enacted in 2009. These communications explained the rules of the RMD holiday and provided instructions for what participants needed to do in order to suspend their RMD for the year. TIAA-CREF sent another round of communications when the U.S. Treasury Department issued rules that allowed participants to return RMD amounts already distributed. Very few participants in our survey returned their RMD after receiving a distribution.

Table 3 shows the percentage of those taking distributions in 2008 who suspended distributions in 2009. We divide the sample between primary and secondary beneficiaries, and between those who took only minimum distributions in 2008 and those who took more than the RMD, either in the form of an annuity or as an additional lump-sum distribution that exceeds the RMD amount. The table shows that just over one third -- 35.5\% -- of the participants who 
received a minimum distribution in 2008 suspended these payouts in 2009. We found the small differences between those who were taking only the RMD (36.5\%) and those who are taking the RMD and another (non-annuity) distribution (35.1\%) in 2008 quite surprising, since one might argue that those taking only the RMD are the most constrained by the RMD rules.

Secondary beneficiaries were significantly less likely to suspend their RMD than primary participants. Secondary beneficiaries with only an RMD had the lowest likelihood of any group of suspending their distribution, with less than 1 in 5 exercising this option.

To place the suspension rate of $35.5 \%$ in context, we calculated the suspension rates for TIAA-CREF participants who were drawing required minimum distributions in 2005, 2006, and 2007. This group is likely to be comparable to, and overlap substantially with, the set of RMD recipients for 2008. The one-year suspension rates from earlier years were substantially lower than the $35.5 \%$ of 2008 recipients who suspended in 2009: 2.2\% of 2005 RMD recipients suspended in 2006, 1.9\% of 2006 recipients suspended in 2007, and 4.2\% of 2007 recipients suspended in 2008.

Figure 2 presents suspension rates of primary participants by deciles of the dollar amount of their 2008 RMD. The data show the likelihood of suspending increased smoothly with the size of the RMD over the first six deciles of the RMD distribution, and that it was roughly constant for the four highest deciles. Participant in the top four deciles were about twice as likely to suspend their distribution as participants in the bottom two deciles. It is helpful to remember that for the lowest deciles, ranked by the amount of the RMD, the distributions are quite modest. In the lowest four deciles, the average RMD is less than $\$ 5,000$.

Participants with large RMDs tend to be those who have large account balances or are older, because, conditional on account balance, the RMD amount is increasing in the 
participant's age. Figure 3 disaggregates primary beneficiaries by the amount of their account balances at year-end 2007, thereby providing cleaner information on the differences in suspension probabilities by account balances. The figure shows a smoothly increasing pattern of suspension rates by account size, with more than a doubling of these rates in moving from the lowest decile to the top four deciles. The highest account balance decile is somewhat more likely to suspend distributions $-47.7 \%$ - than participants in the second highest (43.7\%) or third highest (41.6\%) deciles. Even for the highest decile, however, the probability of suspending distributions is less than 50\%. The data in Figure 3 challenge the view that those with large account balances would not choose to take distributions in the absence of the RMD rules.

Figure 4 presents additional detail on the link between total account balance and suspension probability, dividing primary participants into categories based on the value of their holdings rather than deciles of these holdings. This figure shows that the marginal relationship between wealth and suspension rates is strongest at lower levels of total account balance, and that after reaching the median balance - about $\$ 250,000$ - there is relatively little effect of a larger balance.

In addition to account balance, the other factor that determines the size of one's RMD is the age of the participant. Figure 5 examines the likelihood of a primary participant suspending their RMD by five-year age categories and deciles of their total TIAA-CREF assets. The figure shows that for most asset deciles, the probability of suspending distributions declines with age. When all participants are aggregated, over $40 \%$ of those participants between the ages of 70 and 75 suspended their RMD. The suspension probability falls steadily: it is only $23 \%$ for participants over the age of 90 . This pattern is consistent with a view that as individuals grow older, their distributions from retirement accounts are more likely to represent a source of 
consumable income, which they are unwilling to forego. It is also consistent with the value of continued tax deferral being greater for those who have a longer remaining life expectancy, and therefore are less willing to take withdrawals.

\subsection{Multivariate Probit Results}

We now consider the relationship between suspension decisions and participant attributes in a multivariate setting. Our univariate results suggest that suspension probability rises with account size and falls with age. Here, we explore these factors jointly and also control for several additional participant characteristics that can be gleaned from administrative records. Table 4 reports the results of estimating probit models in for the decision to suspend distributions in 2008. The table shows the estimated marginal effects of each variable on the probability of suspension, along with standard errors for these marginal effects. We include controls for fiveyear age groups, age 75-79, 80-84, 85-89, and 90+. The youngest group, aged less than75 years, is the excluded category. We also include indicator variables for whether the participant is male, whether he or she is married, the natural log of the assets that the participant held at the TIAA CREF complex, and indicator variables for the frequency with which the participant currently receives withdrawals. The variable measuring the assets held at TIAA-CREF is an imperfect measure of participant wealth. It could be low, for example, because a participant holds a small share of a large portfolio at TIAA-CREF, or because the participant has relatively little wealth, most of which is held at TIAA-CREF. These two participants might behave very differently in response to a distribution holiday. The two variables describing the frequency of withdrawals an indicator for one annual payment and an indicator for monthly payments - can be viewed as proxies for whether the individual is relying on RMD amounts to finance retirement 
consumption. We view those who have chosen monthly payouts as more likely to be financing consumption with this income stream.

The multivariate findings confirm the age gradient we found in our univariate results. Across all specifications, the likelihood of suspending an RMD in 2009 is monotonically decreasing with age. Relative to the omitted category of individuals between the ages of $701 / 2$ and 74, when the specification includes only demographic information on the participant's age, marital status, and gender, the probability of suspending drops by approximately 5, 8, 10 and 18 percentage points as we move up each 5-year age range. This finding is consistent with older individuals being more reliant on plan distributions to finance their consumption. When we include additional covariates, such as the total assets held at TIAA-CREF and the participant's asset allocation to fixed income and guaranteed return investment vehicles, the differential between the oldest age group and the rest declines to about 10 percentage points. This reflects a correlation between age and asset allocation.

The estimated differential in the probability of suspension for men versus women is also sensitive to the set of covariates included. When we include only demographic variables, men appear to be 4 percentage points more likely to suspend than women, but when we include the total value of assets, this difference drops to 1.6 percentage points. Married participants are between 2.5 and 3.4 percentage points more likely to suspend. This could reflect the fact that they have a longer joint life expectancy than a single individual, and thus may be more concerned about holding onto assets to insure later life consumption, or it could reflect the fact that they are typically in more favorable economic circumstances than single individuals. This estimated effect of being married does not change when we control for total assets held. 
There is a substantial correlation between suspension probability and RMD payment frequency. We find that participants receiving monthly payments in 2008 were about 10 percentage points less likely to suspend than those taking quarterly withdrawals, and about 17 percentage points more likely to suspend than those taking annual withdrawals. These results are consistent with the interpretation that individuals who take more frequent withdrawals are more likely to be using the RMDs to finance retirement consumption, whereas those taking annual draws are more likely to view their RMD as a forced distribution.

The value of assets held at TIAA-CREF has an economically and statistically significant effect on the suspension probability. A 10 percentage point increase in total assets raises the likelihood of suspension by about 0.5 percentage points. Participants who hold a larger share of their assets in either guaranteed investment or fixed income products are less likely to suspend, even when we condition on the total value of their TIAA-CREF portfolio. In one sense this is surprising: the value of the tax deferral associated with a tax-qualified account is greater for an asset that generates interest income, or other types of income that are taxed as ordinary income, than for a common stock that generates dividend and capital gains income, both of which were taxed at preferential rates in 2009. It is possible that the investors who are most conservative in their portfolio allocation are interested in stable income flows, and that they are consequently less likely to alter their distributions.

We also find that an indicator of whether or not the individual uses a TIAA-CREF financial adviser is significantly related to the likelihood of suspension. Those who do use such an adviser are about $6.6 \%$ more likely to suspend than those who do not. This may reflect the advisers being more aware of the changes in the rules governing withdrawals than the participants themselves, and it suggests that the advisers may have encouraged participants to 
take advantage of the holiday. Two caveats are in order, however, for interpreting this as a causal effect of advisers. First, many TIAA CREF participants use financial advisers who are not affiliated with TIAA CREF. Although we cannot assess the importance of such behavior from our administrative records alone, the participant survey described below informs this issue. Among the subset of individuals who answered our survey, while only $14 \%$ are classified in the administrative records as using a TIAA-CREF adviser, $48 \%$ report that they use a financial adviser. This may understate the effect of having an adviser. Second, use of an adviser is likely to be related to the participant's total wealth, and it may be that higher wealth individuals are more likely to suspend regardless of whether they have an adviser or not. If so, this would overstate the effect of an adviser. To partly control for this possibility, we include the total value of TIAA-CREF assets in our specification. Even so, we caution against interpreting this coefficient as an estimate of the causal effect of using a financial adviser.

Our finding that higher wealth individuals are more likely to suspend is consistent with them either having sufficient other income to finance their consumption, which enables them to take advantage of the favorable tax treatment of their tax-qualified account for a longer time, or having assets that are held outside the tax-qualified system that can be drawn down in lieu of qualified plan withdrawals. It is also likely that those with higher balances face higher marginal tax rates than their lower-wealth counterparts, so the value of tax deferral is likely to be greater for them. This creates an additional incentive to hold assets in tax-qualified accounts.

In several of the specifications in Table 4, we include the value of the assets that TIAACREF manages on behalf of the participant. In addition to the direct effect, we are also interested in whether the effect of other variables varies with the size of the account. To explore this issue, we re-estimated the model shown in column 6 of Table 4 separately for five quintiles 
of the participant wealth distribution, stratifying participants based on the value of their assets at TIAA-CREF. Table 5 presents the results of this estimation. The negative age gradient appears to be slightly stronger at higher wealth quintiles, although the pattern of coefficients is not monotonic. The general pattern, however, is consistent with older individuals with fewer resources being more likely to rely on distributions to finance consumption and thus less likely to suspend. If one compares those taking monthly draws to those taking annual draws (which can be done by subtracting the two coefficients, where the excluded group is those taking quarterly or semi-annual withdrawals), the difference is increasing across the wealth quintiles. For example, in the lowest quintile those taking monthly draws are 11 percentage points less likely to suspend distributions than those taking annual withdrawals. This differential monotonically increases across the wealth quintiles to a nearly 20 percentage point differential in the top quintile. One interpretation of this pattern is that individuals in the top quintile who are taking annual distributions are especially likely to be constrained by the RMD rules, whereas those with fewer resources and who are taking monthly distributions, are much more likely to be dependent on the distributions to finance consumption.

\section{Understanding Suspension Decisions: Survey Evidence on TIAA-CREF Participants}

The summary information on the behavior of TIAA-CREF participants offers insight on the fraction of those making withdrawals from tax-qualified plans who may be constrained by RMDs, but it does not provide much insight on the motives underlying the choices that participants make. To explore this issue, in March and May 2014 we carried out a survey of TIAA-CREF participants who were affected by RMD rules in 2009. The survey population began with our panel of 63,859 TIAA-CREF participants who received distributions in 2008. We excluded participants who were on a "do not contact" list at TIAA-CREF or fell under other 
contact restriction protocols. We randomly selected 29,960 (46.9\%) of the remaining individuals and contacted them with an email survey. Twenty-three percent of those contacted responded with complete surveys, yielding a sample of 6,956 survey respondents. One selection bias in our sample arises from our limiting the survey universe to those who were still alive in 2014. Another is that our sample may over-represent those who are interested in, or think about, taxrelated planning issues in retirement.

The survey consisted of sixteen questions designed to help us better understand the key drivers of RMD suspension behavior. The questions can be grouped into three broad categories related to (1) awareness of the one year RMD suspension, (2) reasons for suspending (or not), and (3) the importance of RMDs and other sources of income for retirement well-being. Fortyeight percent of the survey respondents indicated they worked with a professional financial adviser, either at TIAA-CREF or elsewhere.

To investigate awareness of the RMD holiday, we asked whether participants were aware at the time (in 2009) that Congress had temporarily changed the tax law so that individuals were allowed to skip taking a distribution for that year. Fifty-five percent of the respondents indicated that they were aware; the remaining 45\% were in a combined "no, don't know, don't remember" category. This may understate the knowledge of the provision at the time if some portion of the $45 \%$ were aware but have since forgotten. Nonetheless, it does indicate that a large fraction of the population may not have responded simply due to lack of knowledge that this option was available. We followed up with a question for those who said they were aware of the distribution holiday, asking how they learned about it. The news media was the most common response, accounting for $63 \%$ of those who remembered knowing about the holiday. This was followed by professional financial advisers (22\%), a family member (3\%), and "another source" (12\%). 
We asked all respondents to gauge the importance of various factors when determining how much money to with withdraw from their retirement accounts each year. Figure 6 shows more than $90 \%$ considered complying with the RMD rules as either very or somewhat important, compared with around 65\% for other factors, which include maintaining their standard of living, minimizing the amount of taxes paid, and covering unusual or unexpected expenses.

A key motive for our survey was to explore the reason those who suspended, or did not suspend, distributions in 2009 chose to do so. We asked survey respondents who had suspended their distributions to rate the importance of four potential factors that might have influenced their decision. Table 6 reports the findings. The potential reason for suspending that attracted the largest share of "very important" responses was "allowing money to continue growing tax free/ save on taxes." More than $80 \%$ of respondents indicated that this was a very important consideration, and only two percent ranked this as unimportant. "Preserving money for older ages" and "don't need the money to support current spending" were ranked "very important" by 50 and $45 \%$ of the respondents respectively, but roughly $15 \%$ of the respondents indicated that each of these factors was not important. Only 3\% of the respondents indicated that they suspended distributions because they thought that the law prevented them from taking a 2009 distribution. This pattern of responses suggests that long-term wealth building goals, and the value of accumulating at the pre-tax rate of return for achieving those goals, were key considerations for those who chose to suspend.

Table 7 reports analogous information for the respondents who did not suspend distributions, and provides insight on the factors that led to their decision. In contrast to the responses about factors that were important in the decision to suspend, no single factor that was identified as "very important" by a majority of the respondents. Roughly one third indicated that 
they "depend on distributions for daily spending needs," and another $27 \%$ listed this as a somewhat important factor in their decision not to suspend. Thirty-nine percent of those who did not suspend, however, indicated that this was not important in their decision-making. Another factor that was rated as very or somewhat important by more than half of the respondents who suspended was "view the RMD as a good guide to appropriate speed of draw-down." Twentyfour percent of respondents listed this as very important, and 38\% as somewhat important.

Two factors that did not appear to be important considerations in suspension decisions were procrastination and a need for immediate access to assets. Eighty-three percent of the respondents who did not suspend dismissed "never got around to it" as not important, and 75\% ranked "want easy access to funds in case of emergency" as not important. The latter response suggests either that participants view their assets held within tax-qualified plans as roughly as accessible as assets held outside such plans, or that participants have sufficient access to other financial assets outside their tax-qualified plans so as not to need to rely on their TIAA-CREF assets in the case of an emergency.

To further explore the responses about needing RMD funds to cover spending needs, and about the value of RMDs as a guide to appropriate draw-down, we assigned our survey respondents to the quintile of 2007 assets under management into which our earlier participant data suggested they would fall. We then tabulated the suspension rate, and the responses to the questions "Do you view the RMD as providing some guidance on how much you can spend each year for the rest of your life without running out of money?" and to "If you were not required to receive the RMD from your account for one year, would you have other resources that you could draw upon to pay for your current spending needs?," for respondents in each quintile. 
Table 8 presents the findings. Just as for the participant universe from the administrative records analyzed in the last section, the suspension rate rises with the respondents' total assets under management at TIAA-CREF. Those in the lowest quintile have a 37\% suspension rate, compared with $48 \%$ for those in the highest quintile. Surprisingly, the percentage of survey respondents who say they could cover their spending needs declines with the amount at TIAACREF, from $88 \%$ (lowest quintile) to $79 \%$ (highest quintile). This raises the possibility that some of those who are in the lowest quintile may have assets at other financial services firms that they use to support consumption.

The survey responses also suggest that those with larger asset holdings at TIAA-CREF are more likely to assign some guidance role to the RMD amounts. The difference of more than twenty percentage points in the response to this question between the participants in the lowest (36\%) and highest (58\%) quintiles may indicate that for those with larger asset holdings, who may rely more on income from assets as a source of household income, the RMD is more salient as a consumption guide. This evidence on the number of participants who regard the RMD as informative is potentially important, because as we noted earlier the RMD rules can lead to very low levels of distributions at older ages.

We also used our survey to learn about the extent to which participants view the RMD amount as a constraint on their distribution profile. Among those who have signed up for the minimum distribution option (MDO) at TIAA-CREF, 54.1\% indicated that they would choose a smaller distribution if they could do so, $40.4 \%$ indicated that they would not change from current practice, and 5.5\% indicated that they would take a larger distribution. The response of the last group is puzzling since they could increase their payout at any time. 
The survey responses suggest substantial heterogeneity in the factors that participants consider when they choose distributions from their tax-qualified plans. Taking advantage of the opportunity for accumulation of assets at the pre-tax rate of return is clearly an important factor for many participants who chose to suspend their distributions in 2009. For those who chose not to suspend, a range of factors appear to have influenced their decision, with no single "most important" consideration. The relationship between withdrawals from retirement accounts and consumption planning warrants further exploration. Even participants with large accumulated balances in their tax-qualified plans reporting that they view RMD requirements as a useful guide to feasible consumption spending.

\section{Conclusions and Future Directions}

Our results provide evidence on the effect of required minimum distribution rules (RMDs) on withdrawals from tax-qualified retirement plans. They suggest that a substantial group of plan participants - our estimates suggest about one third - would not take distributions in a given year if it were not for these requirements. This average, however, masks considerable heterogeneity by age and income. The younger elderly and wealthier individuals are more likely to suspend when given the opportunity. The probability that a participant with a retirement account balance of less than $\$ 50,000$ suspended distributions was about $24 \%$, compared with $34 \%$ for a participant with a balance between $\$ 100,000$ and $\$ 150,000$, and just over $40 \%$ for those with a balance above $\$ 250,000$. We found very little difference in suspension probabilities as a function of account balance above $\$ 250,000$.

These results also inform the tax versus retirement security trade-offs that exist when policy makers are designing rules governing distributions from tax-deferred retirement accounts. On the one hand, we find that a substantial fraction of participants rank tax considerations as 
important and would prefer to allow their accounts to grow tax free. This provides some support for the role of RMD regulations to limit the revenue cost of tax deferrals on assets not used to finance consumption in retirement. On the other hand, we find that many individuals view the RMD rules as informative with regard to the sustainability of their retirement distributions, despite the fact that strict adherence to RMD rules would lead to very low distributions at advanced ages.

Our empirical evidence also provides a starting point for analyzing how changes in the RMD rules might affect federal revenues. There have been some proposals, including those advanced by Warshawsky (1998) and by the U.S. Congress Joint Economic Committee (2002), to remove minimum distribution requirements, raise the age at which they take effect, or to reform them to allow substantially greater flexibility for retirees. The revenue consequences of such changes depend on how they affect the total value of distributions.

In our data sample, the average distribution for primary beneficiaries, beneficiaries who had also accumulated the account, fell from \$20,073 in 2008 to \$11,500 in 2009 - a 43\% decline. Because average account balances at the end of the prior year fell nearly $19 \%$, from $\$ 494,590$ to $\$ 401,823$, between these years, the ratio of distributions to account value for those affected by RMDs in 2008 declined from 4.06\% to 2.86\%. Distributions other than RMDs, for example annuities and optional distributions, rose modestly as a share of assets between 2008 and 2009, so the total value of distributions from these accounts declined from $5.54 \%$ in 2008 to $4.54 \%$ in 2009. If our results can be extrapolated to the broader population of qualified plan holders -- and the larger average size of the accounts in our sample relative to the population suggests caution in doing this -- then they suggest that the near-term effect of eliminating RMD rules might be a decline of roughly $20 \%$ in taxable distributions from qualified plans affected by these rules. 
We are not aware of any data on the aggregate value of retirement plan assets that are subject to the RMD rules. This is a key input for revenue analysis. In 2011, 13.0 million tax returns reported $\$ 217.3$ billion in taxable IRA distributions. In addition, 26.8 million returns reported $\$ 581.2$ billion in pension and annuity income, although much of this income, for example payments from defined benefit plans, is not the result of RMD rules. If all IRA distributions were the result of RMD rules, but none of the pension and annuity income was triggered by RMDs, then a 20\% decline in distributions associated with a relaxation of RMD rules would translate to a $\$ 43.4$ billion decline in distributions. At an average tax rate of $20 \%$ on the recipients, this would imply a revenue loss of $\$ 8.7$ billion. If half of the payouts in the pension and annuity income category were also the result of RMDs, this estimate would more than double. These estimates are both substantially greater than the $\$ 3.8$ billion revenue estimate offered by the Joint Committee on Taxation when scoring this provision in 2008.

Although our results provide insight on the factors that affect distribution behavior, there remain data limitations. First, we only observe accounts at one financial institution, whereas the RMD rules apply to the set of all assets that participants hold in qualified plans. Participants with accounts at two financial institutions are permitted to satisfy the RMD rules by taking distributions only from one firm. Thus, it is possible that some participants who were taking distributions from TIAA-CREF accounts in 2008 changed the financial institution from which they were taking distributions for 2009, while continuing to take such distributions. Participants who did so would show up in our data as suspending distributions, while in fact they would have continued such distributions. Issues such as this are inherent to the use of participant-based data from a single financial institution. Sample survey data can overcome this limitation, at the cost 
of typically much less accurate information on participant account balances and decisions and at the risk of reporting error and recall bias.

Second, we observe only the distributions, not whether the distributions affect consumption. It is possible that participants reinvest these payouts in financial accounts outside the qualified plan structure. For analyzing the revenue effects of changes to RMD rules, this distinction is inconsequential. For analyzing whether changes to RMD rules might affect longterm retirement security, however, it is critical. Once again, there is a tradeoff between administrative record data and household survey data for answering this question.

Third, we must caution that our study is based on a one-year suspension of the RMD rules, and that the steady-state effects of increasing the RMD age might differ from the one-year effect. The fraction of retirees who choose not to withdraw assets at age 73, for example, when they have already made withdrawals at ages 71 and 72, may differ from the fraction that chooses to forego a distribution if the RMD age is raised to $731 / 2$, because in the new policy regime some 73 year-olds might find themselves with a need for distributions to support consumption. 


\section{References}

Bershadker, Andrew and Paul Smith. 2006. "Cracking Open the Next Egg: IRA Withdrawals and Retirement Finance," Proceedings of the 98th Annual Conference on Taxation. Washington: National Tax Association.

Brown, Jeffrey R., Jeffrey R. Kling, Sendhil Mullainathan, and Marian V. Wrobel. 2013. "Framing Lifetime Income," Journal of Retirement 1, 27-37.

Bryant, Victoria L. 2008. "Accumulation and Distribution of Individual Retirement Arrangements, 2004." Statistics of Income Bulletin (Spring), 90-101.

Holden, Sarah and Steven Bass. 2012. The IRA Investor Profile: Traditional IRA Investors' Withdrawal Activity, 2007 and 2008. Washington: Investment Company Institute.

Lusardi, Annamaria and Olivia S. Mitchell. 2014. "The Economic Importance of Financial Literacy: Theory and Evidence." Journal of Economic Literature.

Madrian, Brigitte and Dennis Shea. 2001. "The Power of Suggestion: Inertia in 401(k) Participation and Savings Behavior." Quarterly Journal of Economics 116(4): 1149-1187.

Mercer Consulting. 2014. "Budget 2014: Pensions are Dead, Long Live Savings?" http://uk.mercer.com/articles/budget2014-pensions-are-dead-long-live-savings (accessed May 31, 2014).

Poterba, James, Steven Venti, and David Wise. 2013. "The Drawdown of Personal Retirement Assets: Husbanding or Squandering?" NBER Working Paper 16675.

Sabelhaus, John. 2000. "Modeling IRA Accumulation and Withdrawals," National Tax Journal 53, 865-876.

Soled, Jay and Bruce Wolk. 2000. "The Minimum Distribution Rules and Their Critical Role in Controlling the Floodgates of Qualified Plan Wealth," BYU Law Review 587-625.

Sun, Wei and Anthony Webb. 2012. "Should Households Base Asset Decumulation Strategies on Required Minimum Distribution Tables?" Working Paper 12-10, Center for Retirement Research at Boston College.

U.S. Congress. Joint Economic Committee. 2002. The Taxation of Individual Retirement Plans: Increasing Choice for Seniors. Washington: U.S. Congress.

U.S. Internal Revenue Service. Various years. Statistics of Income: Individual Income Tax Returns, Publication 1304. Washington: Internal Revenue Service.

Warshawsky, Mark J. 1998. "The Optimal Design of Minimum Distribution Requirements for Retirement Plans," Benefits Quarterly. No. 4. 
Table 1: Applicable Distribution Period for Married Account Owners with Spousal Beneficiaries and Age Disparity of Less than Ten Years

\begin{tabular}{|c|c|c|}
\hline Age & Distribution Period & Required Withdrawal (\% of Previous Year-End Balance) \\
\hline 70 & 27.4 & $3.65 \%$ \\
\hline 71 & 26.5 & 3.77 \\
\hline 75 & 22.9 & 4.37 \\
\hline 80 & 18.7 & 5.35 \\
\hline 85 & 14.8 & 6.76 \\
\hline 90 & 11.4 & 8.77 \\
\hline 95 & 8.6 & 11.63 \\
\hline 100 & 6.3 & 15.87 \\
\hline 105 & 4.5 & 22.22 \\
\hline 110 & 3.1 & 32.26 \\
\hline$>115$ & 1.9 & 52.63 \\
\hline
\end{tabular}

Source: IRS Publication 590, Individual Retirement Arrangements, Appendix C, Table III, and authors' calculations. 
Table 2: Descriptive Statistics: Suspension-Eligible TIAA-CREF Participants, 2009

\begin{tabular}{|l|c|c|c|}
\hline & Mean & Median & Standard Deviation \\
\hline Age in 2009 $(\mathrm{N}=66,849)$ & 76.7 & 76.7 & 6.4 \\
\hline - Primary Participants $(\mathrm{N}=63,859)$ & 77.4 & 76.8 & 4.5 \\
\hline - Secondary Beneficiaries $(\mathrm{N}=2,990)$ & 61.6 & 59.2 & 15.3 \\
\hline Male & .568 & 1.0 & \\
\hline Married & .674 & 1.0 & \\
\hline 2007 Assets & 485,313 & 233,302 & 644,537 \\
\hline - Primary & 494,591 & 240,854 & 651,277 \\
\hline - Secondary & 287,176 & 134,006 & 433,448 \\
\hline 2008 RMD & 19,573 & 6,765 & 52,350 \\
\hline - Primary & 20,073 & 7,045 & 53,354 \\
\hline - Secondary & 8,891 & 3,025 & 18,831 \\
\hline 2009 RMD & 11,140 & 1,663 & 42,581 \\
\hline - Primary & 11,500 & 1,801 & 43,446 \\
\hline - Secondary & 3,453 & 0 & 12,668 \\
\hline 2010 RMD & 20,091 & 6,163 & 66,385 \\
\hline - Primary & 20,771 & 6,549 & 67,668 \\
\hline - Secondary & 5,576 & 507 & 22,623 \\
\hline
\end{tabular}

Source: Authors' tabulations using TIAA-CREF Participant Database.

Table 3: Probability of Suspending 2009 RMD Distribution among 2008 RMD Distributors

\begin{tabular}{|l|c|c|c|c|}
\hline \multirow{2}{*}{ Beneficiary Type } & \multicolumn{4}{|c|}{ Distribution Type } \\
\cline { 2 - 5 } & RMD Only & RMD + Annuity & RMD + Other & Total \\
\hline Primary & $37.2 \%$ & $32.1 \%$ & $36.4 \%$ & $36.1 \%$ \\
\hline Secondary & 19.5 & 25.4 & 28.5 & 22.7 \\
\hline Total & 36.5 & 32.0 & 35.1 & 35.5 \\
\hline
\end{tabular}

Source: Authors' tabulations. See text for further details. 
Table 4: Determinants of Probability of Suspending RMD - Marginal Effects from Probit Models

\begin{tabular}{|c|c|c|c|c|c|c|}
\hline & Model 1 & Model 2 & Model 3 & Model 4 & Model 5 & Model 6 \\
\hline Age 75-79 & $\begin{array}{r}-0.0548 \\
(0.0025)\end{array}$ & $\begin{array}{r}-0.0519 \\
(0.0053)\end{array}$ & $\begin{array}{r}-0.0425 \\
(0.0054)\end{array}$ & $\begin{array}{r}-0.0403 \\
(0.0055)\end{array}$ & $\begin{array}{r}-0.0395 \\
(0.0056)\end{array}$ & $\begin{array}{r}-0.0371 \\
(0.0052)\end{array}$ \\
\hline Age $80-84$ & $\begin{array}{r}-0.0836 \\
(0.0038)\end{array}$ & $\begin{array}{r}-0.0777 \\
(0.0080)\end{array}$ & $\begin{array}{r}-0.0710 \\
(0.0090)\end{array}$ & $\begin{array}{r}-0.0667 \\
(0.0091)\end{array}$ & $\begin{array}{r}-0.0606 \\
(0.0085)\end{array}$ & $\begin{array}{r}-0.0572 \\
(0.0080)\end{array}$ \\
\hline Age 85-89 & $\begin{array}{r}-0.1049 \\
(0.0047)\end{array}$ & $\begin{array}{r}-0.0858 \\
(0.0088)\end{array}$ & $\begin{array}{r}-0.1612 \\
(0.0205)\end{array}$ & $\begin{array}{r}-0.0928 \\
(0.0126)\end{array}$ & $\begin{array}{r}-0.0793 \\
(0.0112)\end{array}$ & $\begin{array}{r}-0.0753 \\
(0.0105)\end{array}$ \\
\hline Age $90+$ & $\begin{array}{r}-0.1824 \\
(0.0082)\end{array}$ & $\begin{array}{r}-0.1536 \\
(0.0157)\end{array}$ & $\begin{array}{r}-0.0087 \\
(0.0205)\end{array}$ & $\begin{array}{r}-0.1498 \\
(0.0204)\end{array}$ & $\begin{array}{r}-0.1102 \\
(0.0156)\end{array}$ & $\begin{array}{r}-0.1071 \\
(0.0150)\end{array}$ \\
\hline Male & $\begin{array}{r}0.0438 \\
(0.0020)\end{array}$ & $\begin{array}{r}-0.0122 \\
(0.0013)\end{array}$ & $\begin{array}{r}-0.0087 \\
(0.0011)\end{array}$ & $\begin{array}{r}-0.0139 \\
(0.0019)\end{array}$ & $\begin{array}{r}-0.0141 \\
(0.0020)\end{array}$ & $\begin{array}{r}-0.0126 \\
(0.0017)\end{array}$ \\
\hline Married & $\begin{array}{r}0.0276 \\
(0.0012)\end{array}$ & $\begin{array}{r}0.0336 \\
(0.0034)\end{array}$ & $\begin{array}{r}0.0332 \\
(0.0042)\end{array}$ & $\begin{array}{r}0.0313 \\
(0.0043)\end{array}$ & $\begin{array}{r}0.0276 \\
(0.0039)\end{array}$ & $\begin{array}{r}0.0266 \\
(0.0037)\end{array}$ \\
\hline $\begin{array}{l}\text { Log TIAA CREF } \\
\text { Assets } 2008\end{array}$ & & $\begin{array}{r}0.0550 \\
(0.0056)\end{array}$ & $\begin{array}{r}0.0689 \\
(0.0088)\end{array}$ & $\begin{array}{r}0.0707 \\
(0.0096)\end{array}$ & $\begin{array}{r}0.0768 \\
(0.0108)\end{array}$ & $\begin{array}{r}0.0740 \\
(0.0104)\end{array}$ \\
\hline Monthly Payment & & & $\begin{array}{r}-0.1017 \\
(0.0129)\end{array}$ & $\begin{array}{r}-0.0982 \\
(0.0134)\end{array}$ & $\begin{array}{r}-0.1010 \\
(0.0142)\end{array}$ & $\begin{array}{r}-0.1004 \\
(0.0140)\end{array}$ \\
\hline Annual Payment & & & $\begin{array}{r}0.0671 \\
(0.0085)\end{array}$ & $\begin{array}{r}0.0728 \\
(0.0099)\end{array}$ & $\begin{array}{r}0.0729 \\
(0.0103)\end{array}$ & $\begin{array}{r}0.0752 \\
(0.0105)\end{array}$ \\
\hline $\begin{array}{l}\text { \% Assets in } \\
\text { Guaranteed Products }\end{array}$ & & & & $\begin{array}{r}-0.1287 \\
(0.0175)\end{array}$ & $\begin{array}{r}-0.1225 \\
(0.0172)\end{array}$ & $\begin{array}{r}-0.1200 \\
(0.0168)\end{array}$ \\
\hline $\begin{array}{l}\text { \% Assets in Fixed } \\
\text { Income Products }\end{array}$ & & & & $\begin{array}{r}-0.0939 \\
(0.0128)\end{array}$ & $\begin{array}{r}-0.0978 \\
(0.0138)\end{array}$ & $\begin{array}{r}-0.1017 \\
(0.0142)\end{array}$ \\
\hline $\begin{array}{l}\text { Total Withdrawals = } \\
\text { MDO Amount? }\end{array}$ & & & & & $\begin{array}{r}0.0822 \\
(0.0116)\end{array}$ & $\begin{array}{r}0.0816 \\
(0.0114)\end{array}$ \\
\hline $\begin{array}{l}\text { Use Financial } \\
\text { Adviser? }\end{array}$ & & & & & & $\begin{array}{r}0.0656 \\
(0.0092)\end{array}$ \\
\hline
\end{tabular}

Notes: Sample size $=63,859$. Probit results are the marginal effects evaluated at the mean. Standard errors are shown in parentheses. 
Table 5: Determinants of Probability of Suspending RMD:

Marginal Effects from Probit Models Stratified by Total Asset Quintile

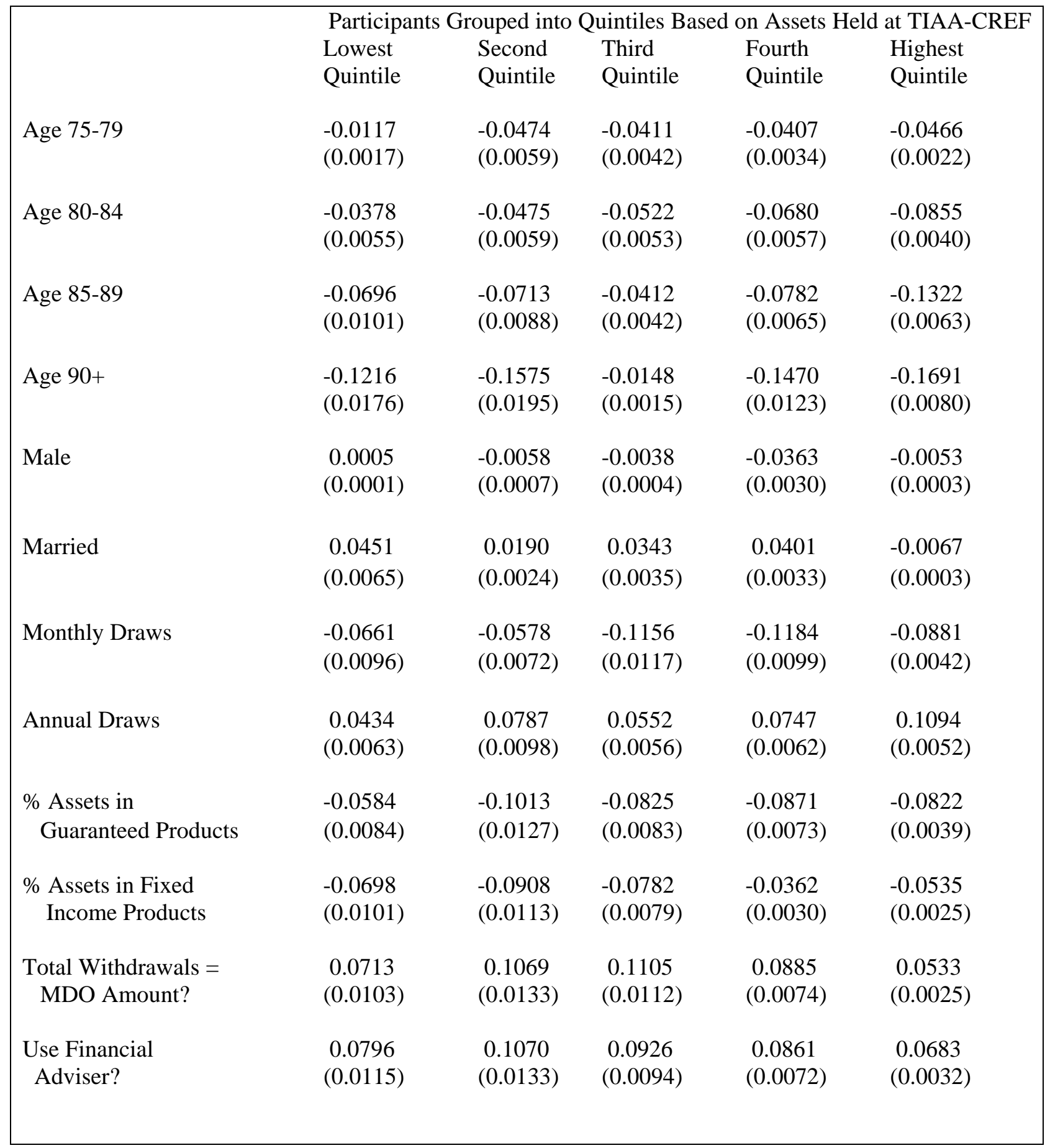


Table 6: Rationale for Suspending Distributions among Suspenders

\begin{tabular}{|l|l|l|l|}
\hline Motive & Very Important & Somewhat Important & Not Important \\
\hline $\begin{array}{l}\text { Allow Money to } \\
\text { Continue to Grow Tax } \\
\text { Free/Postpone Paying } \\
\text { Taxes }\end{array}$ & $81.7 \%$ & $16.2 \%$ & $2.1 \%$ \\
\hline $\begin{array}{l}\text { Preserve More Money } \\
\text { for Older Ages }\end{array}$ & 49.7 & 34.9 & 15.4 \\
\hline $\begin{array}{l}\text { Don't Need the } \\
\text { Money to Support } \\
\text { Current Spending }\end{array}$ & 44.7 & 41.7 & 13.6 \\
\hline $\begin{array}{l}\text { Thought I was not } \\
\text { Allowed to Take a } \\
\text { Distribution in 2009 }\end{array}$ & 3.4 & 4.6 & 91.9 \\
\hline
\end{tabular}

Source: Authors' tabulations using from survey responses from TIAA-CREF distribution recipient survey described in text.

Table 7: Rationale for Not Suspending Distributions (Among Non-Suspenders)

\begin{tabular}{|l|l|l|l|}
\hline Motive & Very Important & Somewhat Important & Not Important \\
\hline $\begin{array}{l}\text { Depend on } \\
\text { Distributions for Daily } \\
\text { Spending Needs }\end{array}$ & $33.8 \%$ & $27.0 \%$ & $39.2 \%$ \\
\hline $\begin{array}{l}\text { View RMD as Good } \\
\text { Guide to Appropriate } \\
\text { Speed of Drawdown }\end{array}$ & 24.0 & 37.5 & 38.5 \\
\hline $\begin{array}{l}\text { Want Easy Access to } \\
\text { Funds in Case of } \\
\text { Emergency }\end{array}$ & 6.1 & 18.8 & 75.1 \\
\hline $\begin{array}{l}\text { Uncertain About What } \\
\text { to do }\end{array}$ & 20.2 & 36.8 & 42.9 \\
\hline Never Got Around to it & 7.7 & 9.5 & 82.8 \\
\hline
\end{tabular}

Source: Authors' tabulations using from survey responses from TIAA-CREF distribution recipient survey described in text.

Table 8: Suspension Rate by Asset Quintile (Survey Participants)

\begin{tabular}{|l|l|l|l|}
\hline Asset Quintile, 2007 & Suspension Rate & $\begin{array}{l}\text { Able to Cover } \\
\text { Spending Needs? }\end{array}$ & $\begin{array}{l}\text { Are RMDs a Guide to } \\
\text { Spendable Amount? }\end{array}$ \\
\hline Lowest $(\mathrm{N}=620)$ & $37.3 \%$ & $88.0 \%$ & $36.0 \%$ \\
\hline Second $(\mathrm{N}=1083)$ & 42.7 & 85.1 & 43.4 \\
\hline Third $(\mathrm{N}=1474)$ & 46.5 & 84.4 & 47.3 \\
\hline Fourth $(\mathrm{N}=2014)$ & 47.4 & 82.0 & 53.6 \\
\hline Highest $(\mathrm{N}=2581)$ & 48.4 & 78.8 & 57.5 \\
\hline
\end{tabular}

Source: Authors' tabulations using from survey responses from TIAA-CREF distribution recipient survey described in text. 
Figure 1: Nominal and Real Value of Required Minimum Distributions

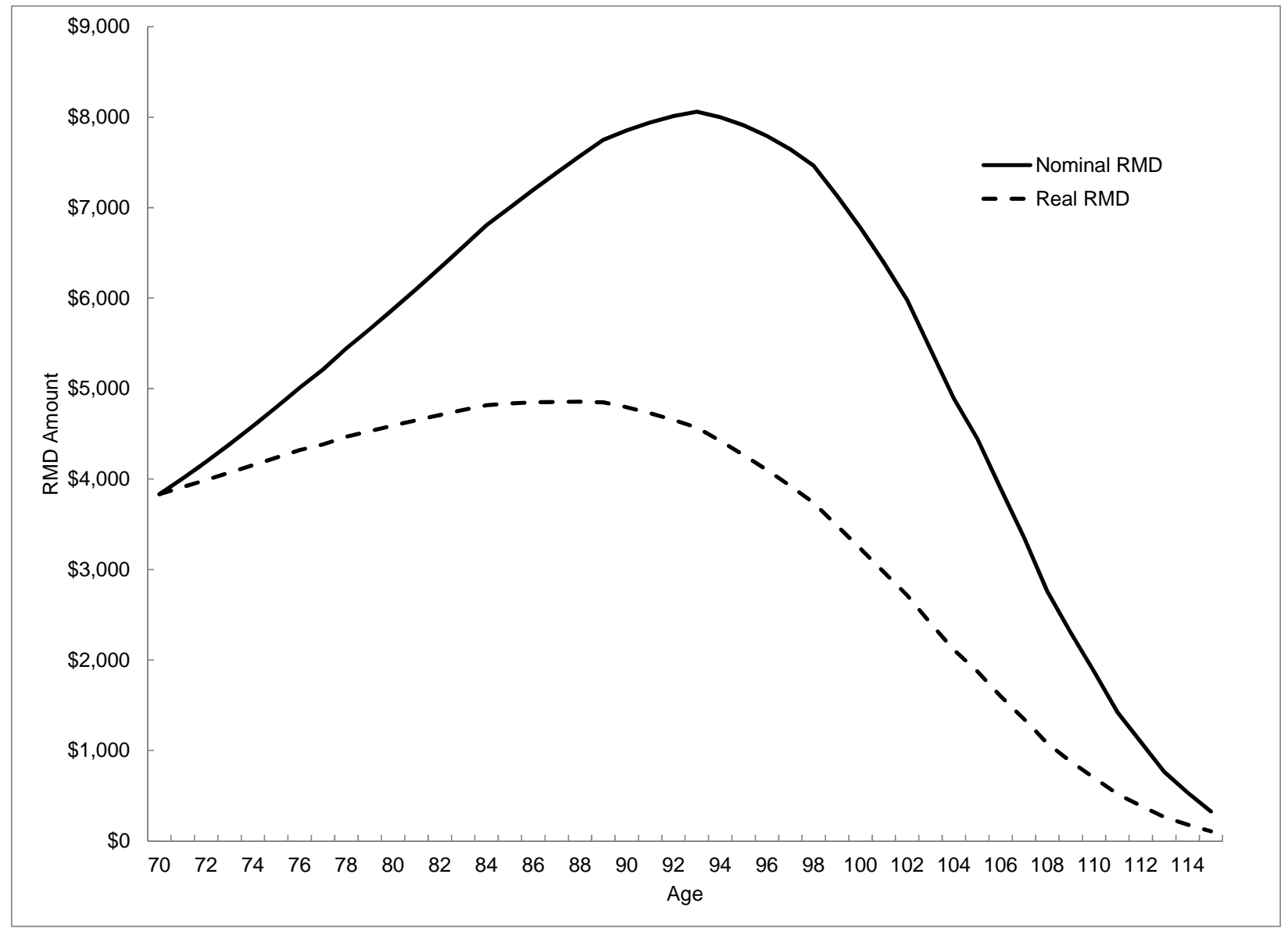

Note: Calculations assume an initial principal of $\$ 100,000$, invested at a nominal $5 \%$ return with a $2.5 \%$ inflation rate. 
Figure 2: Probability of Suspending Distribution in 2009 by Decile of 2008 Distribution

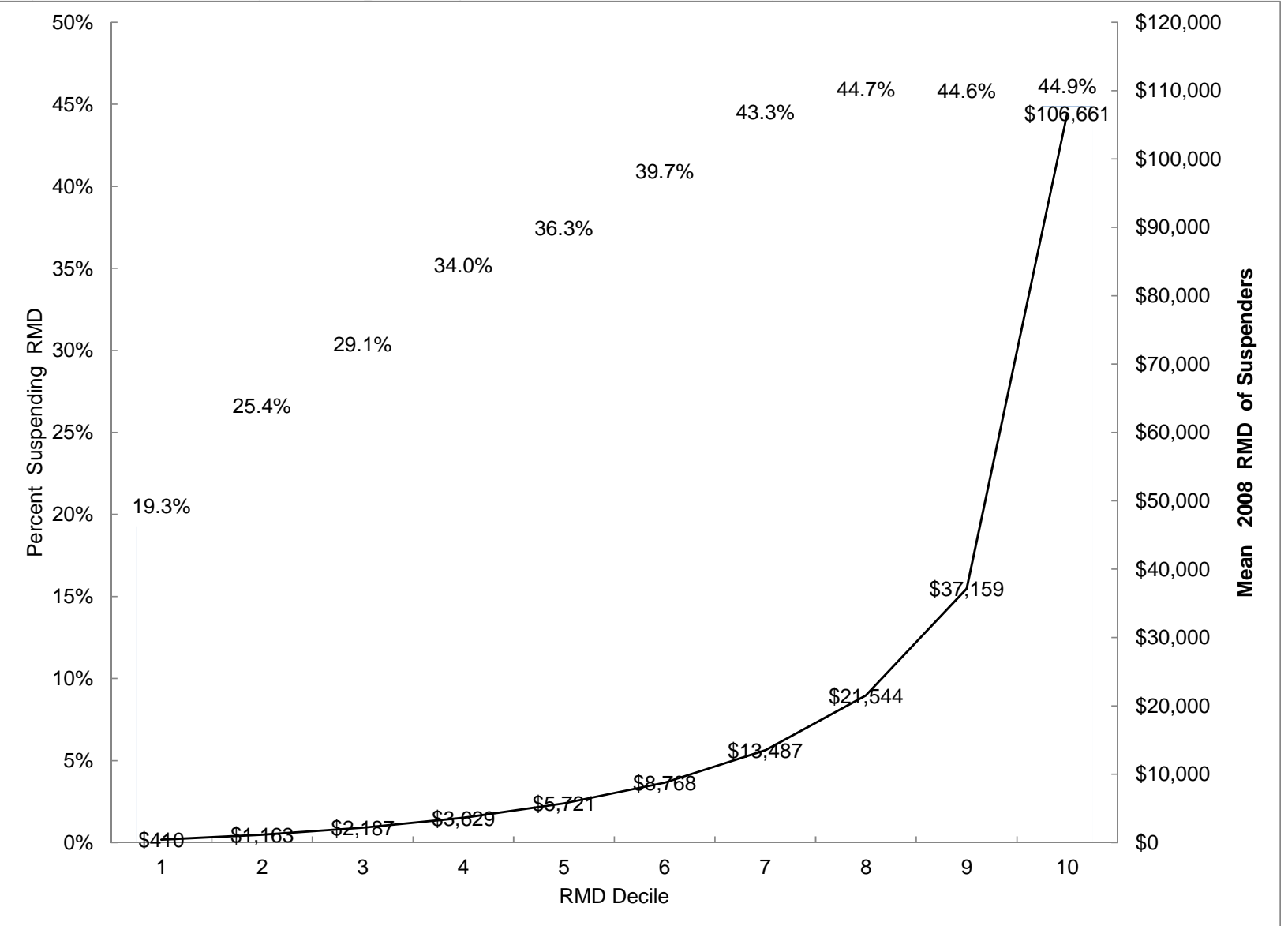

Source: Authors' tabulations of TIAA-CREF data as described in the text. 
Figure 3: Probability of Suspending Distribution in 2009 by Decile of Total TIAA-CREF Assets

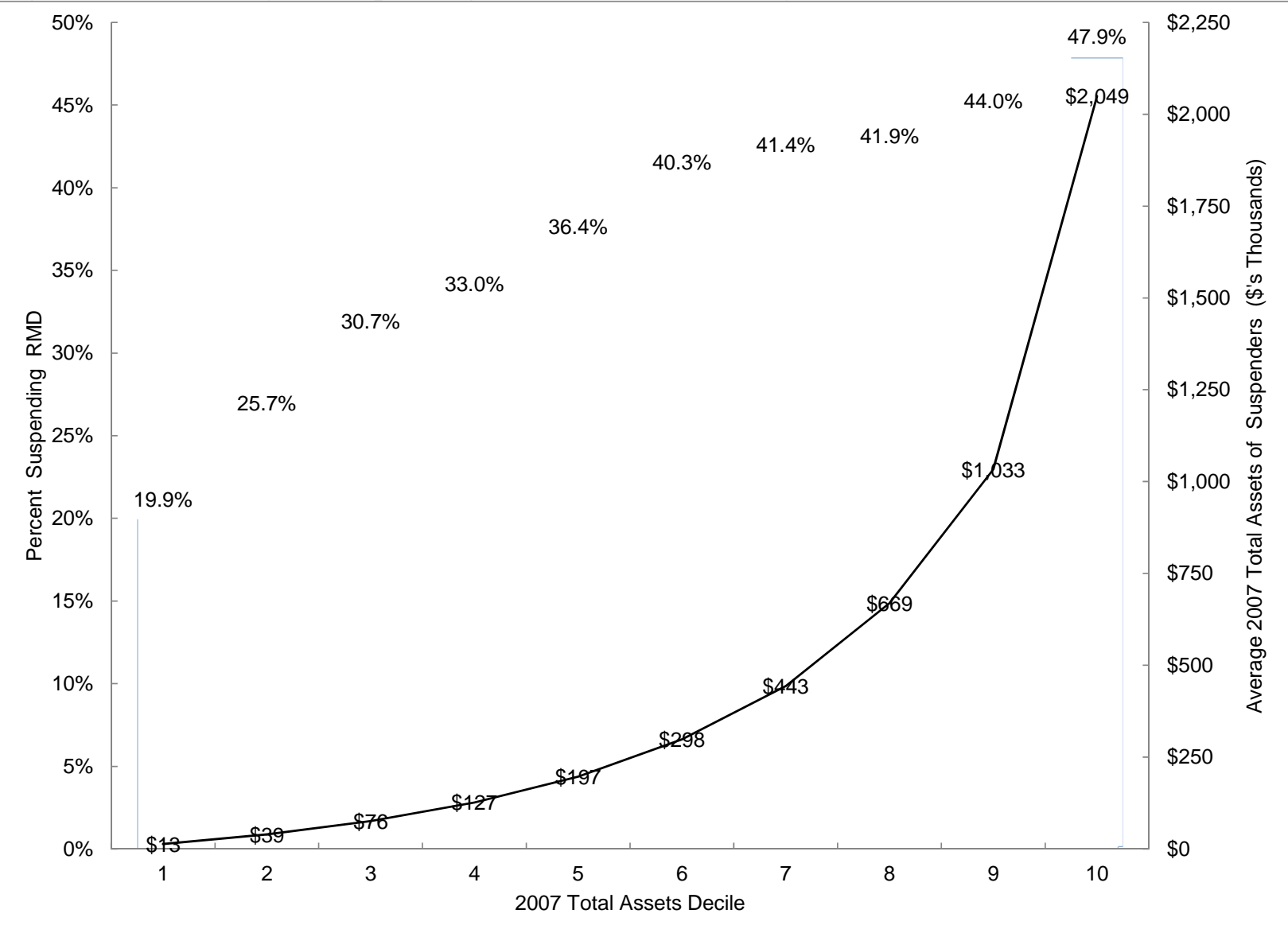

Source: Author tabulations of TIAA-CREF as described in the text. 
Figure 4: Probability of Suspending 2009 Distribution by Amount of 2008 TIAA-CREF Assets

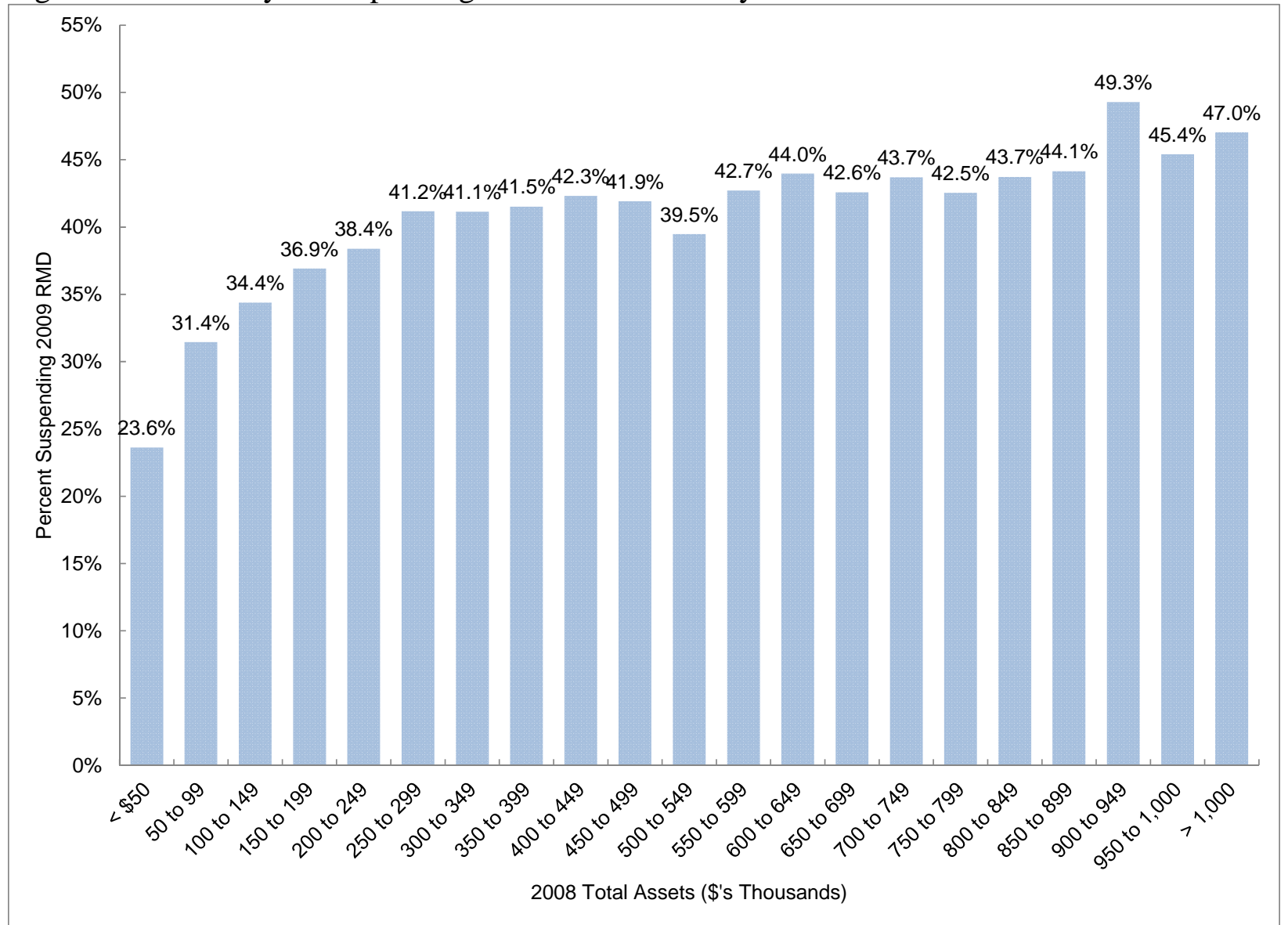

Source: Authors' tabulations of TIAA-CREF data as described in the text. 
Figure 5: Probability of Suspending Distribution in 2009, by 2007 TIAA-CREF Assets and Age

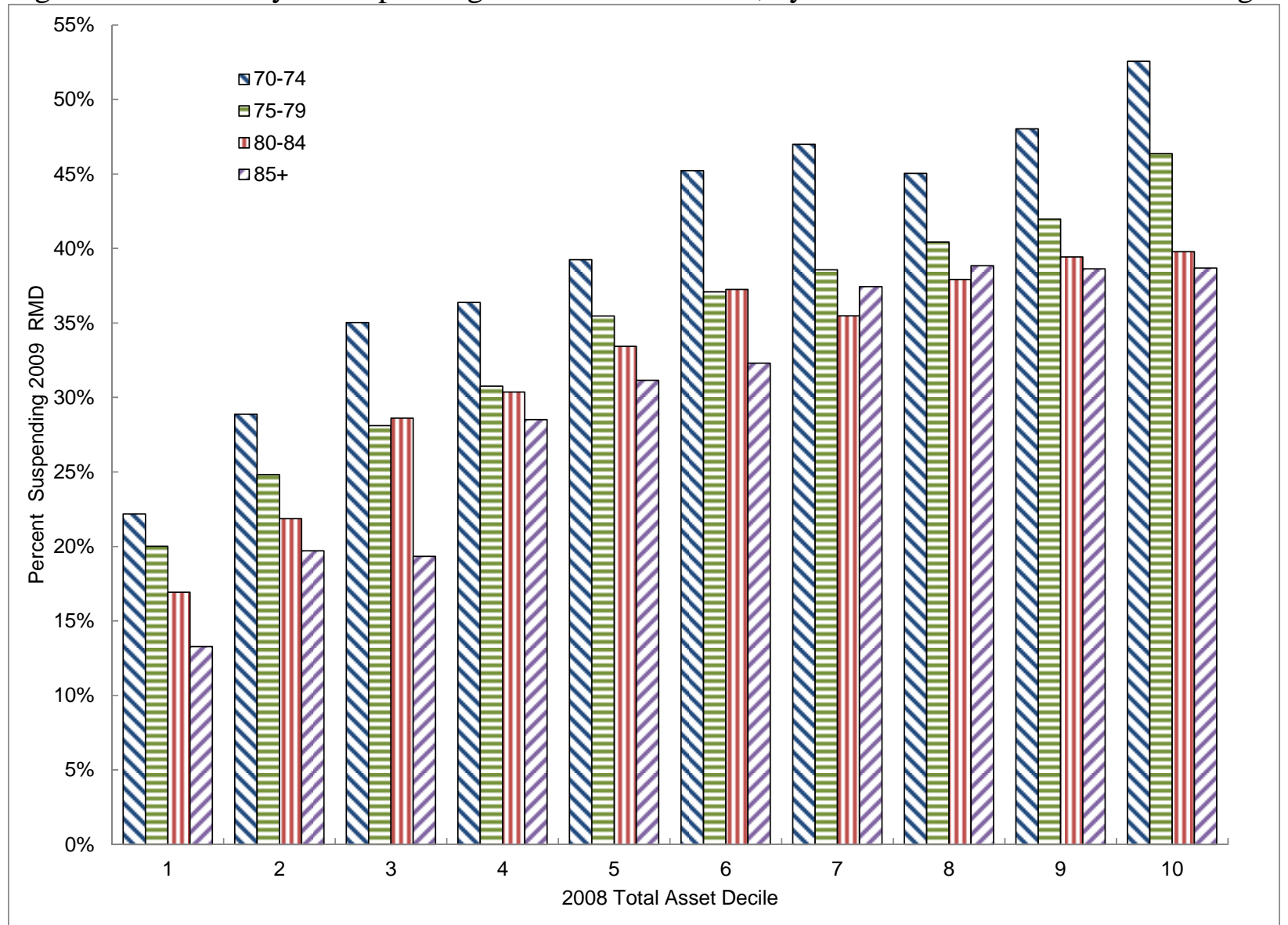

Source: Authors' tabulations of TIAA-CREF data as described in the text. 
Figure 6: Importance of Various Factors in Determining Retirement Distribution

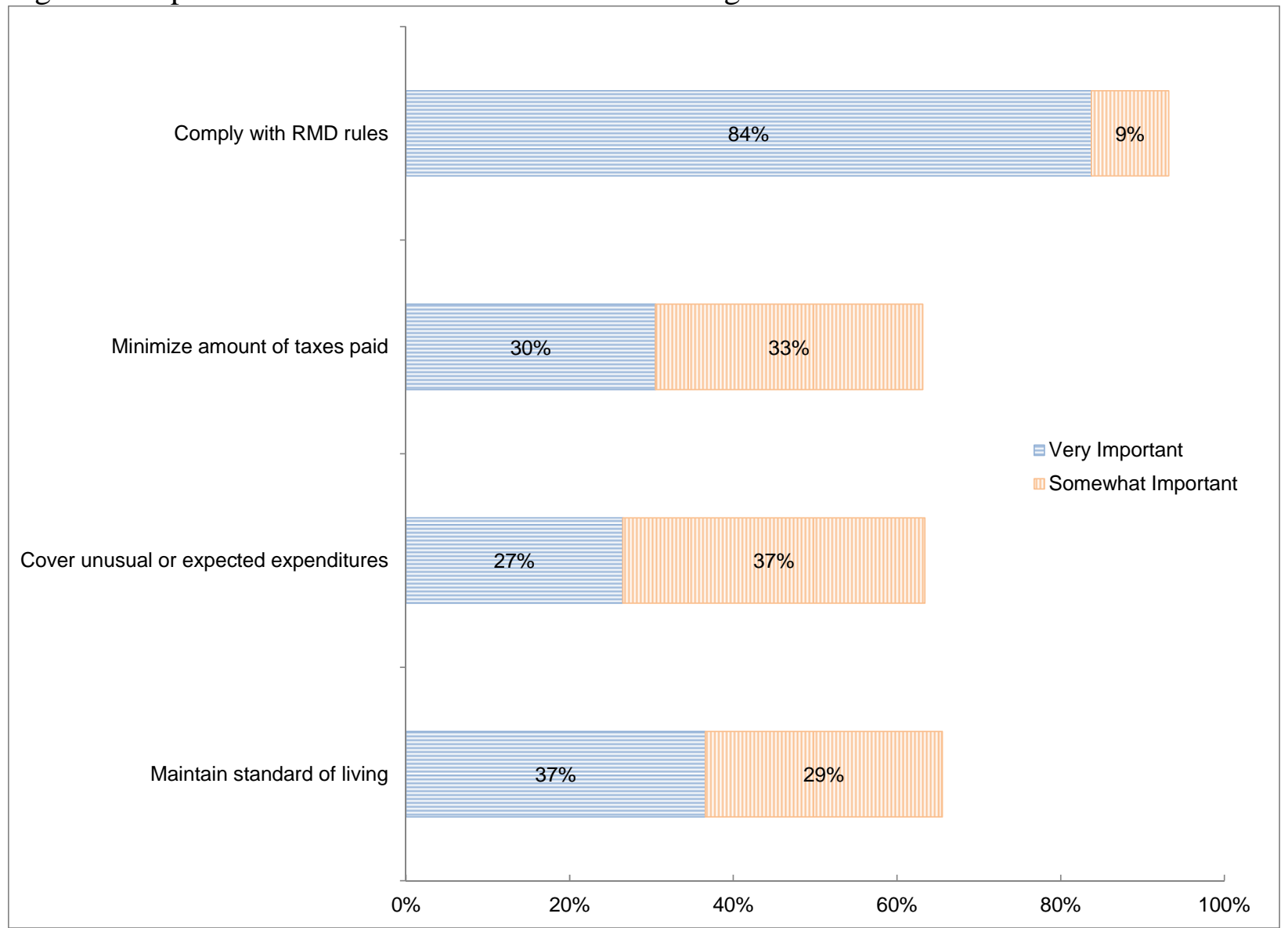

Source: Authors' tabulations of survey data from TIAA-CREF as described in the text. 